\title{
Risk factors for pre-eclampsia/eclampsia among working women in Mexico City
}

\author{
Prudencia Cerón-Mireles ${ }^{a}$, Siobán D. Harlow ${ }^{b}$, Constanza Ivette Sánchez-Carrillo ${ }^{a}$ and Rosa María Núñez \\ ${ }^{a}$ Centro Nacional de Salud Ambiental, Dirección General de Salud Ambiental, Metepec, Estado de Mexico, Mexico, ${ }^{b}$ Department of Epidemiology, \\ University of Michigan, Ann Arbor MI, USA and ${ }^{~}$ Instituto Nacional de Salud Publica, Cuernavaca, Morelos, Mexico
}

Correspondence:

Dr Siobán D. Harlow, Department of Epidemiology, 109 Observatory St., Ann Arbor, MI 48109, USA.

E-mail: harlow@umich.edu

\section{Summary}

This study examined risk factors for pre-eclampsia/eclampsia in a population-based sample of pregnant working women in Mexico City. Over a 3-month period, all women who gave birth at three major hospitals and who had worked for at least 3 months during pregnancy were interviewed. After excluding mothers with multiple gestations or infants with birth defects, and previous diagnoses of hypertension, chronic renal disease or diabetes, 131 of 2436 women (5.4\%) had been diagnosed with pre-eclampsia and/or eclampsia. The frequency was much higher among women of low socio-economic status: $12 \%$ of uninsured women (SSA) compared with $4.2 \%$ of private sector employees (IMSS) and 1.3\% of public sector employees (ISSSTE). After adjusting for education, women working in services $(\mathrm{OR}=1.68,95 \% \mathrm{CI}=1.01,2.81)$ and in retail $(\mathrm{OR}=1.99,95 \% \mathrm{CI}=1.18,3.37)$, primiparae $(\mathrm{OR}=2.64,95 \% \mathrm{CI}=1.65,4.21)$ and women whose pregestational weight was $\geqslant 55 \mathrm{~kg}(\mathrm{OR}=2.02,95 \% \mathrm{CI}=1.34,3.04)$ were at increased risk. Efforts to develop and evaluate intervention programmes should target hospitals serving the uninsured (SSA) if reduction in the number of preventable maternal deaths in Mexico is to be achieved. Such programmes should also target service and retail workers and identify women with poor glycaemic control early in pregnancy.

\section{Introduction}

Pre-eclampsia and eclampsia are major complications of pregnancy and leading causes of maternal death throughout the world. A recent study of maternal mortality in Mexico City estimated the maternal mortality ratio in 1988-89 to be $114: 100000 .{ }^{1}$ More than three-quarters of the deaths were considered preventable, the principle cause being the hypertensive diseases of pregnancy. ${ }^{1}$ Although the aetiology of pre-eclampsia and eclampsia remains somewhat uncertain, multiple pathophysiological mechanisms have been proposed. ${ }^{2-4}$ Information on the maternal factors that may place a woman at increased risk for preeclampsia and eclampsia is limited. Using national data from the United States, Saftlas et al. ${ }^{5}$ identified young age and single motherhood as important demographic risk factors. Primiparous women also appear to be at increased risk. ${ }^{6}$ In two large cohorts of pregnant women, Sibai and colleagues ${ }^{7,8}$ identified systolic and diastolic blood pressure at cohort entry during the second trimester, prepregnancy obesity and smoking history to be important predictors of preeclampsia among primiparae.

Although occupation and working conditions have been associated with various adverse pregnancy outcomes, including low birthweight and preterm delivery, few studies have examined occupational risk factors for pre-eclampsia. Three studies in the United States $^{9-11}$ and one in Australia ${ }^{12}$ found an increased risk for pre-eclampsia among women who worked during their pregnancy compared with women who did not. Eskenazi et al. ${ }^{13}$ reported an increased risk among women occupationally exposed to solvents. Two studies have reported that women in jobs 
characterised by high occupational strain have a twofold elevation in risk when compared with other working women. ${ }^{11,14}$

In Mexico, the participation of women of reproductive age in the work force has increased over the past few decades, rising from $19 \%$ in $1970^{15}$ to $31.4 \%$ in $1990 .^{16}$ Thus, understanding whether and how occupational factors may influence the health of pregnant women is increasingly important. This paper evaluates the frequency of and risk factors for pre-eclampsia/ eclampsia using data obtained as part of a large population-based study of birthweight and gestational age of infants born to working mothers in Mexico City.

\section{Materials and methods}

The study population consisted of all pregnant women who delivered a singleton birth at one of three large hospitals in Mexico City, during a 3-month period in 1992, and who indicated that they had worked for at least 3 months during their pregnancy. A detailed description of the study methodology has been published previously. ${ }^{17}$ Briefly, one major hospital was selected from each of the three main health systems in Mexico that provide medical care to private sector employees (IMSS), government sector employees (ISSSTE) and the uninsured (SSA). A total of 2663 of 2767 women (96.2\%) who reported working during pregnancy were interviewed in hospital prior to discharge. Mothers who gave birth to infants with congenital defects $(n=40)$ or who had been previously diagnosed with hypertension $(n=119)$, chronic renal disease $(n=46)$ or diabetes $(n=22)$ were excluded, resulting in a final study population of 2436 working women.

All study procedures were approved by the Commission of Investigation of the National Institute of Public Health of Mexico. We interviewed participants in the hospital after delivery and subsequently abstracted their medical records. The structured questionnaire included information on sociodemographic and lifestyle characteristics including age, level of education, marital status, height, and smoking history, as well as on characteristics of the woman's social support network, medical history and pregnancy history (e.g. number of prenatal visits, gravidity, pregravid weight and history of pregnancy loss). Parity was defined as the number of previous pregnancies that had resulted in a livebirth or a stillbirth.

We defined women as having pre-eclampsia if a diagnosis of either pre-eclampsia or eclampsia appeared in their medical records. At the time of this study, procedural guidelines in all three hospitals defined pre-eclampsia as a syndrome characterised by the presence of hypertension, proteinuria and oedema, and eclampsia as the subsequent development of convulsions. Two hospitals, IMSS and ISSSTE, provided explicit criteria for mild and severe pre-eclampsia based on having a diastolic blood pressure of $>90$ and $>100 \mathrm{mmHg}$ respectively.

Hospital of delivery can be considered a marker of socio-economic status (SES) as utilisation of SSA hospitals is an indicator of low SES just as use of Medicaid is in the USA. Social support was measured by two variables including whether or not the woman had a confidant and whether or not she had material support, defined as someone she could ask for financial help.

Occupational information included type of occupation as coded by the Mexican Classification of Occupations, ${ }^{18}$ length of the working week, work shift, number of hours spent standing per day, use of industrial machines, whether or not the job required physical effort, whether or not the women was exposed to chemicals, extreme temperature, noise or conflicts at work and whether or not she had a permanent job. Mexican labour law entitles women to 6 weeks of antenatal leave and 6 weeks of post-partum leave; however, for occupations such as domestic work and for temporary workers, the right to maternity benefits depends on the goodwill of the employer. Information on maternity benefits included whether or not the participant had maternity leave benefits, the number of weeks of antenatal leave used, whether or not her job activity was modified during pregnancy (e.g. change of work station or reduction of daily work hours) and total number of days of sick leave.

Frequency distributions were calculated for each covariate and the association between independent variables was examined using chi-square tests, $t$-tests and correlations as appropriate. Crude odds ratios (OR) with $95 \%$ confidence intervals (CI) were calculated for each demographic, occupational, obstetric history and social support variable. As both the risk of pre-eclampsia/eclampsia and many of the demographic and occupational characteristics varied dramatically by hospital of delivery, we calculated crude ORs stratified by hospital of delivery to evaluate whether hospital of delivery confounded or modified the observed associations with pre-eclampsia/eclampsia. Finally, variables found to be associated with pre- 
eclampsia/eclampsia in the unadjusted analyses were evaluated, using multiple logistic regression to calculate adjusted ORs and their 95\% CIs.

\section{Results}

A total of 131 women had had a diagnosis of preeclampsia $(n=102)$, eclampsia $(n=22)$ or both $(n=7)$ yielding a prevalence of $5.4 \%$ in this population of working women. Of the 2436 eligible births, $71.1 \%$ occurred at the IMSS (private sector employees) hospital, 9.7\% at the ISSSTE (public sector employees) hospital and 19.2\% at the SSA (uninsured) hospital (Table 1). Most women had more than 4 years of formal education. The median age of the mothers was 25 years, with $11.2 \%<20$ years old and $8 \% \geqslant 35$ years. Eighteen per cent were single.

One-third of the women were employed as clerical workers and $22 \%$ were employed in retail. The

Table 1. Unadjusted odds ratios for pre-eclampsia by sociodemographic, occupational, obstetric and social support characteristics for 2436 working mothers in Mexico City

\begin{tabular}{|c|c|c|c|}
\hline \multirow[b]{2}{*}{ Variable } & \multirow[b]{2}{*}{$n$} & \multicolumn{2}{|c|}{ Pre-eclampsia/eclampsia } \\
\hline & & Rate & OR $[95 \% \mathrm{CI}]$ \\
\hline \multicolumn{4}{|c|}{ Demographic characteristics } \\
\hline \multicolumn{4}{|c|}{ Hospital } \\
\hline SSA & 467 & $12.0 \%$ & $3.1[2.2,4.5]$ \\
\hline IMSS & 1733 & $4.2 \%$ & 1.0 Reference \\
\hline ISSSTE & 236 & $1.3 \%$ & $0.3[0.1,1.0]$ \\
\hline \multicolumn{4}{|l|}{ Age (years) } \\
\hline$<20$ & 274 & $9.1 \%$ & $2.0[1.3,3.2]$ \\
\hline $20-34$ & 1966 & $4.8 \%$ & 1.0 Reference \\
\hline$>34$ & 196 & $6.1 \%$ & $1.3[0.7,2.4]$ \\
\hline \multicolumn{4}{|c|}{ Education (years) } \\
\hline$<4$ & 174 & $12.0 \%$ & $4.1[2.0,8.6]$ \\
\hline $4-12$ & 1882 & $5.2 \%$ & $1.6[0.9,3.0]$ \\
\hline$>12$ & 371 & $3.2 \%$ & 1.0 Reference \\
\hline Missing & 9 & & \\
\hline \multicolumn{4}{|l|}{ Marital status } \\
\hline Married & 1992 & $7.1 \%$ & $1.5[1.0,2.2]$ \\
\hline Single & 438 & $5.0 \%$ & 1.0 Reference \\
\hline Missing & 6 & & \\
\hline \multicolumn{4}{|c|}{ Occupational characteristics } \\
\hline \multicolumn{4}{|c|}{ Occupation } \\
\hline Clerical & 818 & $3.4 \%$ & 1.0 Reference \\
\hline Professional & 381 & $3.7 \%$ & $1.1[0.6,2.1]$ \\
\hline Industry & 365 & $5.2 \%$ & $1.6[0.9,2.0]$ \\
\hline Services & 545 & $7.5 \%$ & $2.3[1.4,3.8]$ \\
\hline Retail & 326 & $8.9 \%$ & $2.8[1.6,4.7]$ \\
\hline Missing & 1 & & \\
\hline
\end{tabular}

\begin{tabular}{|c|c|c|c|}
\hline \multirow[b]{2}{*}{ Variable } & \multirow[b]{2}{*}{$n$} & \multicolumn{2}{|c|}{ Pre-eclampsia/eclampsia } \\
\hline & & Rate & OR $[95 \% \mathrm{CI}]$ \\
\hline \multicolumn{4}{|c|}{ Has a permanent job } \\
\hline Yes & 1427 & $3.3 \%$ & 1.0 Reference \\
\hline No & 1004 & $8.4 \%$ & $2.7[1.9,3.9]$ \\
\hline Missing & 5 & & \\
\hline \multicolumn{4}{|c|}{ Has no antenatal leave benefits } \\
\hline Yes & 1564 & $3.8 \%$ & 1.0 Reference \\
\hline No & 864 & $8.3 \%$ & $2.3[1.6,3.3]$ \\
\hline Missing & 8 & & \\
\hline \multicolumn{4}{|c|}{ Obstetric history } \\
\hline \multicolumn{4}{|c|}{ Parity } \\
\hline 0 & 1074 & $6.8 \%$ & $2.1[1.4,3.1]$ \\
\hline $1-2$ & 1061 & $3.4 \%$ & 1.0 Reference \\
\hline$\geqslant 3$ & 299 & $7.4 \%$ & $2.3[1.3,3.9]$ \\
\hline Missing & 2 & & \\
\hline \multicolumn{4}{|c|}{ Prepregnancy weight $(\mathrm{kg})$} \\
\hline$<55$ & 1104 & $3.7 \%$ & 1.0 Reference \\
\hline$\geqslant 55$ & 1020 & $6.4 \%$ & $1.8[1.2,2.6]$ \\
\hline Missing & 312 & & \\
\hline \multicolumn{4}{|c|}{ Smoked during pregnancy } \\
\hline No & 2295 & $5.4 \%$ & $0.8[0.3,1.9]$ \\
\hline Yes & 120 & $4.2 \%$ & 1.0 Reference \\
\hline Missing & 21 & & \\
\hline \multicolumn{4}{|c|}{ Prenatal care } \\
\hline No & 93 & $7.5 \%$ & $1.5[0.7,3.2]$ \\
\hline Yes & 2339 & $5.3 \%$ & 1.0 Reference \\
\hline Missing & 4 & & \\
\hline \multicolumn{4}{|c|}{ Number of prenatal visits } \\
\hline$<3$ & 197 & $6.1 \%$ & $1.1[0.6,2.1]$ \\
\hline $4-12$ & 1818 & $5.4 \%$ & 1.0 Reference \\
\hline$>12$ & 314 & $3.8 \%$ & $0.7[0.4,1.3]$ \\
\hline Missing & 107 & & \\
\hline \multicolumn{4}{|c|}{ Social support } \\
\hline \multicolumn{4}{|c|}{ Has a confidant } \\
\hline Yes & 2042 & $4.8 \%$ & 1.0 Reference \\
\hline No & 390 & $8.5 \%$ & $1.8[1.2,2.8]$ \\
\hline Missing & 4 & & \\
\hline \multicolumn{4}{|c|}{ Has help in an emergency } \\
\hline Yes & 2023 & $4.7 \%$ & 1.0 Reference \\
\hline No & 397 & $8.8 \%$ & $1.9[1.3,2.9]$ \\
\hline Missing & 16 & & \\
\hline
\end{tabular}

remaining women were about equally distributed between professional, industrial and service occupations. Forty-one per cent of the women did not have a permanent job and $35.5 \%$ had no antenatal leave benefits. In addition, $15.7 \%$ of the women worked $>$ $50 \mathrm{~h}$ per week, $20 \%$ stood $\geqslant 8 \mathrm{~h}$ per day and $6.6 \%$ worked a rotating or night shift. A total of $21.4 \%$ of the women reported that their jobs involved considerable 
physical effort but only $4.2 \%$ used industrial machines. Women were more likely to move to less arduous tasks while pregnant $(31.6 \%)$ or take sick leave $(40.1 \%)$ than to reduce the number of hours they worked each day $(10.2 \%)$.

As would be expected in a working population, many women were primiparous (44.1\%) and $41.9 \%$ reported weighing $\geqslant 55 \mathrm{~kg}$ pregestationally. Most women in Mexico City receive some prenatal care, thus only $3.8 \%$ of the women had received no prenatal care. Few women in Mexico smoke and only $4.9 \%$ reported smoking during their pregnancy. Only a small proportion of the women $(16 \%)$ were without emotional or material social support.

Large differences were observed in the frequency of pre-eclampsia/eclampsia by socio-economic status (Table 1) with $12 \%$ of women delivering at the public assistance hospital (SSA) and only $4.2 \%$ and $1.3 \%$ of those delivering at the IMSS and ISSSTE hospitals, respectively, having this outcome. The odds for presenting with pre-eclampsia/eclampsia were 3.1 times higher among women delivering at the SSA hospital than among women delivering at IMSS [95\% $\mathrm{CI}=2.2$, 4.5]. Similarly, women with $<4$ years of education had a fourfold higher risk of pre-eclampsia/ eclampsia than women who had completed high school. Occupation was also an important marker of pre-eclampsia/eclampsia risk. Both women who worked in services and those who worked in retail had more than twice the risk of pre-eclampsia/ eclampsia when compared with clerical workers. Women who did not have permanent jobs were nearly three times at risk. However, working conditions related to potential for fatigue, including length of the work week, hours spent standing, having a job which required physical effort, and use of industrial machines, were not associated with the crude odds of having pre-eclampsia/eclampsia (data not shown). With the exception of having antenatal leave benefits, labour benefits such as change of activities, reductions in length of the work day and use of sick leave, were also not associated with these conditions (data not

\begin{tabular}{|c|c|c|c|c|}
\hline & $\begin{array}{c}\text { ISSSTE } \\
\%\end{array}$ & $\begin{array}{c}\text { IMSS } \\
\%\end{array}$ & $\begin{array}{c}\text { SSA } \\
\%\end{array}$ & $\chi^{2}(P$-value $)$ \\
\hline Age (years) & & & & $161.0(<0.001)$ \\
\hline$<20$ & 1.3 & 8.8 & 25.5 & \\
\hline $20-34$ & 80.5 & 84.3 & 67.5 & \\
\hline$>34$ & 18.2 & 6.9 & 7.1 & \\
\hline Education (years) & & & & $382.5(<0.001)$ \\
\hline$<4$ & 0 & 3.3 & 25.1 & \\
\hline $4-12$ & 65.7 & 80.3 & 73.2 & \\
\hline$>12$ & 34.3 & 16.3 & 1.7 & \\
\hline Single & 8.1 & 12.9 & 42.0 & $227.0(<0.001)$ \\
\hline Occupation & & & & $711.0(<0.001)$ \\
\hline Clerical & 46.6 & 39.2 & 6.2 & \\
\hline Professional & 47.3 & 15.4 & 0.9 & \\
\hline Industry & 1.3 & 16.5 & 16.5 & \\
\hline Services & 0 & 12.8 & 22.3 & \\
\hline Retail & 5.1 & 16.2 & 54.2 & \\
\hline Job not permanent & 17.4 & 29.2 & 98.3 & $786.2(<0.001)$ \\
\hline Has no antenatal leave benefits & 12.7 & 22.1 & 97.0 & $956.8(<0.001)$ \\
\hline Parity & & & & $101.8(<0.001)$ \\
\hline 0 & 30.9 & 47.4 & 38.8 & \\
\hline $1-2$ & 56.8 & 43.6 & 36.8 & \\
\hline$\geqslant 3$ & 12.3 & 9.0 & 24.4 & \\
\hline Prepregnancy weight $\geqslant 55 \mathrm{~kg}$ & 56.1 & 48.5 & 39.8 & $14.6(<0.001)$ \\
\hline Smoked during pregnancy & 5.1 & 4.3 & 7.3 & $6.8(0.03)$ \\
\hline No prenatal care & 0 & 0.7 & 17.4 & $289.2(<0.001)$ \\
\hline Has no confidant & 9.7 & 12.8 & 31.3 & $101.6(<0.001)$ \\
\hline Has no help in an emergency & 9.8 & 11.0 & 39.7 & $227.6(<0.001)$ \\
\hline
\end{tabular}

Table 2. Sociodemographic, occupational, obstetric and social support characteristics of 2436 working mothers in Mexico City stratified by health system of delivery hospital 
shown). Women with no antenatal leave benefits had had a twofold higher risk of pre-eclampsia/eclampsia than those who did have antenatal leave benefits.

The risk of pre-eclampsia/eclampsia was doubled among teenagers, in primiparous women and in women of high parity. Women who were above the mean for prepregnancy weight had a $75 \%$ increase in their risk. No association was observed between these conditions and marital status, smoking or use of prenatal care. Lack of either emotional or material social support almost doubled the crude odds of pre-eclampsia/eclampsia.

When we examined the distribution of risk characteristics by hospital of delivery (Table 2), the risk characteristics were also found to vary greatly by SES. Among women delivering at the SSA hospital, 25\% were $<20$ years of age as compared with $1.3 \%$ and $8.8 \%$ at the ISSSTE and IMSS hospitals respectively. Similarly, $25 \%$ of women delivering at the SSA hospital had $<4$ years of education as compared with zero and $3.3 \%$ at the ISSSTE and IMSS hospitals. Obstetric risks also differed somewhat by hospital of delivery, with women delivering at IMSS most likely to be primiparous and women delivering at ISSSTE most likely to have a prepregnancy weight of $\geqslant 55 \mathrm{~kg}$. Lack of emotional or material support was much more frequent among women delivering at the SSA.

Women delivering at the ISSSTE hospital were about equally distributed between clerical and professional occupations, whereas over half the women at the SSA hospital worked in retail, with the remainder working predominantly in industry or in services. More than $95 \%$ of the women delivering at the SSA did not have a permanent job and did not have antenatal leave benefits. When we examined the association between these two occupational characteristics and pre-eclampsia/eclampsia among women delivering at ISSSTE and IMSS only, having no antenatal leave benefits was not associated with disease risk $(\mathrm{OR}=1.20)$ while the risk among women with an insecure job was substantially reduced $(\mathrm{OR}=1.58,95 \% \mathrm{CI}=0.98,2.55)$. One-third of the women delivering at the SSA worked $>50 \mathrm{~h}$ a week and stood for 8 or more hours a day, compared with only $5 \%$ of working women delivering at ISSSTE.

No evidence of effect modification by hospital was observed in the stratified analyses (data not shown). Given the strong association between hospital of delivery and both other measures of socio-economic status, only education and occupation were included in the adjusted models and these variables were
Table 3. Adjusted ${ }^{\mathrm{a}}$ odds ratios for pre-eclampsia/eclampsia for 2436 working mothers in Mexico City

\begin{tabular}{ll}
\hline Risk factor & OR $[95 \% \mathrm{CI}]$ \\
\hline Less than 4 years of education & $2.6[1.2,5.5]$ \\
4-12 years of education & \\
$\quad$ Not service or retail occupations & 1.0 Reference \\
Service occupations & $1.8[1.0,3.0]$ \\
$\quad$ Retail occupations & $2.2[1.3,3.9]$ \\
More than 12 years of education & $0.7[0.4,1.4]$ \\
Parity & \\
0 & $2.7[1.7,4.2]$ \\
$1-2$ & 1.0 Reference \\
$\geqslant 3$ & $1.7[0.9,3.5]$ \\
Prepregnancy weight $>55 \mathrm{~kg}$ & $2.0[1.3,3.1]$ \\
\hline
\end{tabular}

${ }^{\mathrm{a} E a c h}$ variable adjusted for all other variables in the table.

modelled as a combined set of dummy variables. Age was strongly associated with both parity and education (data not shown), and thus only the last two variables were included in the adjusted models. Among women with 4-12 years of education, occupation remained an important risk factor for preeclampsia/eclampsia with a $75 \%$ increase in risk among women working in services and more than a twofold increase in risk among women working in retail (Table 3) as compared with other women with a similar level of education working in clerical, professional or industrial occupations. The only other risk factors that remained important in the adjusted models were parity and prepregnancy weight. Primiparous women had more than a two and a half fold increase in risk as compared with women having their second or third child. Women who weighed $\geqslant 55 \mathrm{~kg}$ were also twice as likely to develop pre-eclampsia/ eclampsia than lower-weight women.

\section{Discussion}

This is the first study of the frequency of and risk factors for pre-eclampsia/eclampsia conducted in Mexican women, although hypertensive disease of pregnancy has previously been reported to be the leading cause of maternal death in Mexico. ${ }^{1}$ We found that low socio-economic status, as measured by delivering at the hospital serving the uninsured, by years of education and by working in either services or retail, increased a woman's risk of having preeclampsia/eclampsia. High prepregnancy weight and primiparity doubled the risk of these conditions regardless of hospital of delivery. 
The frequency of pre-eclampsia/eclampsia observed in this population-based sample of women who gave birth in specified hospitals in Mexico City $(5.4 \%)$ is higher than the frequency of $2.6 \%$ reported in a US study based on surveillance of hospital discharge data ${ }^{5}$ but similar to the frequency of $5.3 \%$ observed in a cohort of healthy women by Sibai and colleagues ${ }^{8}$ and of $5.2 \%$ in a Swedish study. ${ }^{19}$ Few studies have examined the effect of socio-economic status on preeclampsia risk. One study of teenagers in Kwa-Zulu Natal which included a measure of SES reported a similar result. ${ }^{20}$ Other studies have found an increased risk for pre-eclampsia among working women compared with women who do not work, ${ }^{9-11}$ but few studies have examined risk by specific occupation. High job strain has been reported to double the risk of pre-eclampsia. ${ }^{11,14}$ In this study, not having a permanent job was weakly associated with pre-eclampsia/ eclampsia; however, almost all women delivering at the SSA had no job security and no maternity leave benefits. Other working conditions that have been identified as important risk factors for low birthweight and preterm delivery, such as having a long work week and standing, were not associated with preeclampsia/eclampsia risk in these data.

Our results regarding the impact of demographic factors and obstetric history, that is increased risk with young age and primiparity, are consistent with results of previous studies in other countries. ${ }^{3,5,10,19}$ The importance of obesity, increased body mass index, or high prepregnancy weight is increasingly identified as one of the more important risk factors for preeclampsia in both developed ${ }^{7,8,10,19,21}$ and developing countries. $^{22}$ Recently, insulin resistance has been identified as one of the pathogenic mechanisms mediating the development of pre-eclampsia and individuals with pre-eclampsia may have clinically silent but persistent insulin resistance. ${ }^{23,24}$

Several potential limitations of this study must be acknowledged. First, as this was a secondary data analysis, information on pre-eclampsia/eclampsia was limited to data on the presence or absence of a diagnosis in the medical record. Thus, the frequency of the condition may have been underestimated. Also, as diagnosis of pre-eclampsia was not standardised, differences in diagnostic practices across the hospitals may have led to differences in observed frequency of the disease. Thus, the difference in risk of preeclampsia/eclampsia across the hospitals may be an artifact. Nonetheless, these data are consistent with maternal mortality data that suggest differences in the risk of maternal death across the three health systems with hypertensive disease of pregnancy being the leading cause of maternal mortality. Future studies should standardise procedures for ascertaining preeclampsia/eclampsia. Second, this study only included women who had worked for at least 3 months during pregnancy; thus, women who stopped work in the first trimester because of health problems and healthy women who chose to stop working early in pregnancy were excluded. Finally, risk factor information was obtained from participants retrospectively and therefore it is possible that recall bias may have influenced some of our results.

Given the striking differences in risk of pre-eclampsia and eclampsia by hospital of delivery, further investigation of specific risk factors for developing pre-eclampsia among uninsured women who are served by the SSA is clearly warranted. Efforts to develop preventive and intervention programmes, and programmes evaluating quality of maternity care, should target the SSA hospitals if reduction in the number of preventable maternal deaths is to be achieved. Given that increasing numbers of women are entering the labour force, and that women who work appear to be at increased risk of preeclampsia, additional attention should also be given to identifying occupational factors that influence women's risk. Our data suggest that a productive strategy for reducing risk of maternal mortality related to preeclampsia/eclampsia may be the development of interventions at the community level targeted to designated occupational groups, and specifically to women working in service and retail. As one of the predominant jobs included in the service category is domestic work (i.e. maids), attention to the needs of this relatively isolated occupational population may deserve special attention. Finally, the increasing recognition of the role of weight and insulin insensitivity in the development of preeclampsia suggests the importance of identifying women with poor glycaemic control early in pregnancy.

\section{Acknowledgements}

This study was funded by a grant from the Ford Foundation.

\section{References}

1 Bobadilla JL, Reyes Frausto S, Karchmer S. The magnitude and causes of maternal mortality in the Federal District (1988-89). Gaceta Medica de Mexico 1996; 132:5-18. 
2 National High Blood Pressure Education Program Working Group. Report on high blood pressure in pregnancy. American Journal of Obstetrics and Gynecology 1990; 163:1691-1712.

3 Berkowitz KM. Insulin resistance and preeclampsia. Clinics in Perinatology 1998; 25:873-885.

4 Friedman SA, Taylor RN, Roberts JM. Pathophysiology of preeclampsia. Clinics in Perinatology 1991; 18:661-682.

5 Saftlas A, Olson D, Franks AL, Atrash HK, Podras P. Epidemiology of preeclampsia and eclampsia in the United States 1979-86. American Journal of Obstetrics and Gynecology 1990; 163:460-465.

6 Zhang J, Zeisler J, Hatch MC, Berkowitz G. Epidemiology of pregnancy-induced hypertension. Epidemiologic Reviews 1997; 19:218-232.

7 Sibai BM, Ewell M, Levine RJ, Klebanoff MA, Esterlitz J, Catalano PM, et al. Risk factors associated with preeclampsia in healthy nulliparous women. The Calcium for Preeclampsia Prevention Study Group. American Journal of Obstetrics and Gynecology 1997; 177:1003-1010.

8 Sibai BM, Gordon T, Thom E, Caritis SN, Klebanoff MA, McNellis D, et al. Risk factors for preeclampsia in healthy nulliparous women. A prospective multicenter study. American Journal of Obstetrics and Gynecology 1995; 172:642-648.

9 Marbury MC, Linn S, Monson RR, Wegman DH, Schoenbaum SC, Stubblefield PG, et al. Work and pregnancy. Journal of Occupational Medicine 1984; 26:415-421.

10 Eskenazi B, Fenster L, Sidney S. A multivariate analysis of risk factors for preeclampsia. JAMA 1991; 266:237-241.

11 Klonoff-Cohen H, Cross JL, Pieper CF. Job stress and preeclampsia. Epidemiology 1996; 7:245-249.

12 Najman JM, Morrison J, Williams GM, Andersen J, Keeping JD. The employment of mothers and the outcomes of their pregnancies: an Australian study. Public Health 1989; 103:189-198.

13 Eskenazi B, Bracken MB, Holford TR, Grady J. Exposure to organic solvents and hypertensive disorders of pregnancy. American Journal of Industrial Medicine 1988; 14:177-188.

14 Marcoux S, Berube S, Brisson C, Mondor M. Job-strain and pregnancy-induced hypertension. Epidemiology 1999; 10:376-382.

15 Rendón T, Pedrero M. El Trabajo de la Mujer en los Setentas. México City: Secretaría de Programación y Presupuesto, Instituto Nacional de Estadística Geografía e Informática, 1990.

16 XI Censo Nacional de Vivienda. Mexico City: Secretaría de Programación y Presupuesto, Instituto Nacional de Estadística, Geografía e Informática, 1990.

17 Cerón-Mireles P, Harlow SD, Sánchez-Carrillo C. The risk of prematurity and small-for-gestational-age birth in Mexico City: the effects of working conditions and antenatal leave. American Journal of Public Health 1996; 86:825-831.

18 Coordinación General de los Servicios Nacionales de Estadística Geografía e Informática. Clasificación Mexicana de Ocupaciones. Mexico City: Secretaría de Programación y Presupuesto, Instituto Nacional de Estadística, Geografía e Informática, 1980.

19 Ros HS, Cnattingius S, Lipworth L. Comparison of risk factors for preeclampsia and gestational hypertension in a population-based cohort study. American Journal of Epidemiology 1998; 147:1062-1070.

20 Dlamini NJ. Factors associated with preeclampsia and quality of care of affected teenagers during labour within health region H in Kwa-Zulu Natal. Curationis 1997; 20:16-22.

21 Kotchen MJ, McKean HE, Kotchen TA. Blood pressure of young mothers and their children after hypertension in adolescent pregnancy: six-to-nine year follow-up. American Journal of Epidemiology 1982; 115:861-867.

22 Mahomed K, Williams MA, Woelk GB, Jenkins-Woelk L, Mudsamiri S, Longstaff $\mathrm{L}$, et al. Risk factors for preeclampsia among Zimbabwean women: maternal arm circumference and other anthropometric measures of obesity. Paediatric and Perinatal Epidemiology 1998; 12:253-262.

23 Kaaja R. Insulin resistance syndrome in preeclampsia. Seminars in Reproductive Endocrinology 1998; 16:41-46.

24 Berkowitz KM. Insulin resistance and preeclampsia. Clinics in Perinatology 1998; 24:873-875. 